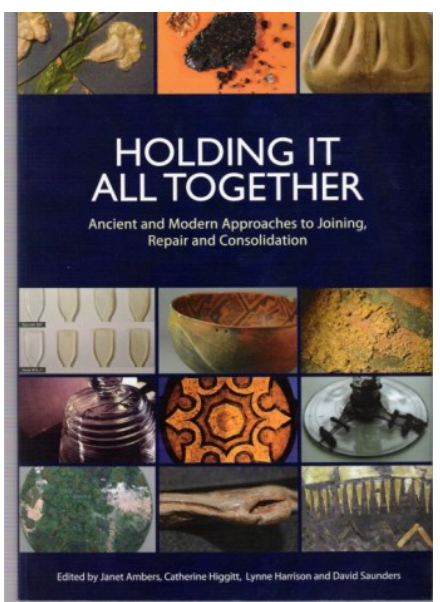

Holding it All Together. Ancient and Modern Approaches to Joining, Repair and Consolidation

VV.AA. Editado por Janet Ambers, Catherine Higgitt, Lynne

Harrison and David Saunders

Archetype Publications in association with

The Bristish Museum. London, 2009

210 páginas, ilustraciones y figuras, 29,6 x $21 \mathrm{~cm}$.

ISBN: 978-1-904982-47-D

La publicación recoge los textos de las comunicaciones presentadas en las sesiones del encuentro celebrado en el Clore Education Center del Museo Británico durante los días 21 y 22 de febrero de 2008. El objetivo de la convocatoria sobre un tema tan genérico como la adhesión y la consolidación era atraer el interés de los profesionales de diferentes disciplinas relacionadas con la conservación del patrimonio -conservadores-restauradores, arqueólogos, antropólogos, historiadores del arte, científicos- buscando la discusión y el intercambio de información desde un planteamiento interdisciplinar, así como el estudio de las técnicas de ejecución.

Está estructurado en tres partes, predominando los textos relacionados con la adhesión y el ensamblado de los materiales silíceos. La primera incluye algunos casos sobre productos y técnicas tradicionales en un contexto tanto arqueológico como etnográfico, agrupándolos según la naturaleza del soporte y su cronología: vidrio, cerámica, metales y materiales orgánicos. Como ejemplos de este primer apartado citaremos el estudio comparativo de adhesivos para vidrio utilizados en época romana y el de otras formulaciones empleadas a principios del siglo XX, también el hallazgo de una reparación original en un propulsor prehistórico de hueso y varias revisiones de antiguas técnicas de reparación efectuadas en cerámicas, metales, manuscritos y mosaicos. En la segunda parte se presentan ponencias sobre adhesivos más modernos en uso a partir del siglo XIX, se exponen los resultados de las investigaciones realizadas sobre el envejecimiento acelerado de adhesivos polivinílicos y acrílicos, una completa revisión del comportamiento y aplicaciones del Paraloid B-72, de los productos empleados habitualmente para la adhesión del vidrio y las vidrieras, también para la escultura en piedra, el papel y la madera. Cabe destacar un trabajo que incide en la importancia de la reversibilidad de los sistemas de ensamblado para el futuro mantenimiento de las obras escultóricas. En la última sección se exponen algunos casos prácticos, como el examen de antiguas reparaciones realizadas en un cuenco de esquisto decorado con aplicaciones metálicas perteneciente a la Edad del Bronce, en una colección de bronces chinos, una revisión de los adhesivos empleados a principios del siglo XX en México y el montaje de un relieve de gran formato en terracota.

La obra va dirigida tanto a los investigadores interesados en el conocimiento de los materiales y las técnicas como a los conservadores- restauradores de arqueología y artes decorativas, resultando una completa revisión de productos tradicionales y actuales empleados para la adhesión y el ensamblado de las obras. Para el investigador, profundizar en el conocimiento de las técnicas y los productos tradicionales le proporcionará una valiosa información sobre la cultura objeto de estudio, sus pautas de comportamiento y sus mecanismos socio-económicos. Para el conservador-restaurador, la revisión de las técnicas tradicionales, el comportamiento de los productos aplicados con el paso del tiempo, la problemática que presenta su conservación como documento histórico y su empleo en la 
actualidad como alternativa a materiales más modernos tiene un enorme interés para la práctica profesional. También conocer el resultado de las investigaciones sobre productos actuales le proporciona una información relevante a la hora de acometer las intervenciones.

Los casos presentados son variados, tanto por la diversidad de soportes que se abordan como por su enfoque histórico, técnico o científico, resultando una recopilación interesante sobre la casuística de la adhesión y el ensamblado de objetos, una revisión de las técnicas y los productos utilizados a lo largo del tiempo, comparando su eficacia, durabilidad, estabilidad, reversibilidad, tanto desde un enfoque científico como práctico. Existían ediciones anteriores con un planteamiento científico como Adhesives and Consolidants Preprints of the Contributions to the IIC Paris Congress (1984), Adhesives and Coatings, Science for Conservators $\mathrm{n}^{\circ} 3$ (1987), C.V. Horie Materials for Conservation: organic consolidants, adhesives and coatings (1990), I. Skeist Handbook of adhesives (1990), pero no teníamos una publicación actualizada que abordara este tema con carácter monográfico, por lo que supone una herramienta de consulta y referencia muy útil para los profesionales y estudiosos del tema.

Ana Laborde Marqueze Instituto del Patrimonio Cultural de España

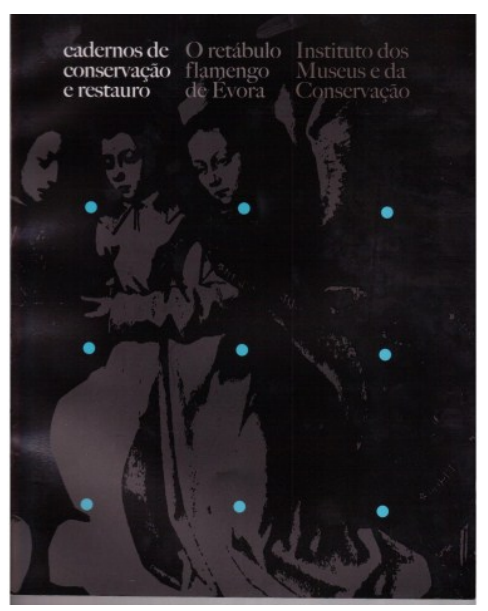

\section{O Retábulo flamengo de Évora - Cadernos de Conservação e restauro $(6 / 7)$}

(eds) Joana Campelo, Alexandre Pais e Nazaré Escobar. Instituto dos Museus e da Conservação

144 páginas, com ilustrações.

Lisboa, 2009

ISBN: 1645 - 1902

A mais recente publicação dos Cadernos de Conservação e Restauro, da responsabilidade do Instituto dos Museus e da Conservação (IMC) está, inteiramente, consagrada às pinturas flamengas pertencentes ao já perdido retábulo da Sé de Évora (Portugal). Treze painéis são dedicados à Vida e Glorificação da Virgem e seis outros, retresentam a Paixão de Cristo, estando datados dos finais do século XV.

Este número (6/7) apresenta o projecto de investigação e de conservação que decorreu entre 2003 e 2008, desenvolvido pelo extinto Instituto Português de Conservação e Restauro (IPCR) em colaboração com o IMC. O projecto reuniu uma extensa equipa constituída de historiadores de arte, químicos, físicos, biólogos, fotógrafos e conservadores-restauradores, que levou a cabo o estudo material e técnico aprofundado, aproveitando o momento da intervenção nas pinturas.

O Caderno está estruturado em cinco artigos principais que, na sua maior parte, são fruto de comunicações feitas no colóquio 'Olhar de Perto - os Primitivos Flamengos do Museu de Évora' que decorreu no Museu Nacional de Arte Antiga (Lisboa), em Abril de 2008. 